\title{
A GESTÃO DO CUIDADO DE ENFERMAGEM FRENTE À PANDEMIA CORONAVÍRUS: UM RELATO DE EXPERIÊNCIA
}

\section{NURSING CARE MANAGEMENT IN FRONT OF THE CORONAVIRUS PANDEMIC: AN EXPERIENCE REPORT}

\section{GESTIÓN DE LA ATENCIÓN DE ENFERMERÍA FRENTE A LA PANDEMIA DE CORONAVIRUS: RELATO DE EXPERIENCIA}

\author{
Camila Medeiros dos Santos ${ }^{1}$, Graciele Oroski Paes ${ }^{2}$
}

Como citar esse artigo: Santos CM, Paes GO. A gestão do cuidado de enfermagem frente à pandemia coronavírus: um relato de experiência. Rev Enferm Atenção Saúde [Internet]. 2021 [acesso em:___ ; 10(3):e202137. doi: https://doi.org/ 10.18554/reas.v10i3.4956

\begin{abstract}
RESUMO
Objetivo: relatar a experiência de uma enfermeira quanto aos desafios enfrentados e estratégias utilizadas na gestão do cuidado a pacientes suspeitos e confirmados de infecção por COVID-19 durante a pandemia do vírus no Brasil. Método: trata-se de um relato de experiência desenvolvido por uma enfermeira gerente na liderança de um setor para o recebimento de pacientes suspeitos ou confirmados pelo vírus em um hospital do estado do Rio de Janeiro, nos meses de abril a julho de 2020. Resultados: a gerência do cuidado envolveu aspectos de estrutura, processo e resultados diretamente relacionados à garantia da assistência segura e de qualidade desenvolvida pelos profissionais de enfermagem. Conclusão: é essencial a presença do enfermeiro na gestão do cuidado de um setor envolvido com pacientes infectados durante o enfrentamento de uma pandemia.
\end{abstract}

Descritores: Cuidados de enfermagem; Pandemias; Infecções por Coronavírus.

\begin{abstract}
Objective: to report the experience of a nurse regarding the challenges faced and strategies used in the management of care for suspected and confirmed patients with COVID-19 infection during the virus pandemic in Brazil. Method: this is an experience report developed by a nurse manager in the leadership of an sector for receiving patients suspected or confirmed by the virus in a hospital in the state of Rio de Janeiro, from April to July 2020. Results: care management involved aspects of structure, process and results directly related to ensuring safe and quality care developed by nursing professionals. Conclusion: the presence of nurses is essential in the care management of a sector involved with infected patients during a pandemic.
\end{abstract}

Descriptors: Nursing Care; Pandemics; Coronavirus Infections.

\footnotetext{
1 Universidade do Estado do Rio de Janeiro - RJ Hospital Universitário Pedro Ernesto. Enfermeira pela Universidade Federal de Juiz de Fora (2007-2011); Mestrado em Enfermagem - FACENF/UFJF; E-mail: camilams.uerj@yahoo.com.br http://orcid.org/0000-0002-7683-8235

${ }^{2}$ Universidade Federal do Rio de Janeiro - RJ; Escola de Enfermagem Anna Nery. Enfermeira pela Escola de Enfermagem Aurora Afonso Costa (EEAAC-1999/2003) da Universidade Federal Fluminense (UFF). PósDoutorado pela Facultad de Enfermería, Fisioterapia y Podologia de la Universidad de Sevilla - España. Departamento de Enfermagem Fundamental - EEAN/UFRJ; http://orcid.org/0000-0001-8814-5770
} 


\section{RESUMEN}

Objetivo: reportar la experiencia de una enfermera sobre los desafíos enfrentados y las estrategias utilizadas en el manejo de la atención de los pacientes sospechosos y confirmados con infección por COVID-19 durante la pandemia de virus en Brasil. Método: se trata de un informe de experiencia desarrollado por una enfermera gerente en el liderazgo de un sector para la recepción de pacientes sospechosos o confirmados por el virus en un hospital del estado de Río de Janeiro, de abril a julio de 2020. Resultados: la gestión del cuidado involucró aspectos de estructura, proceso y resultados directamente relacionados con la garantía de un cuidado seguro y de calidad desarrollado por los profesionales de enfermería. Conclusión: la presencia de enfermeras es fundamental en la gestión asistencial de un sector involucrado con pacientes infectados durante una pandemia.

Descriptores: Atención de Enfermería; Pandemias; Infecciones por Coronavirus.

\section{INTRODUÇÃO}

O surto mundial do novo Coronavírus Severe Acute Respiratory Syndrome Coronavirus 2 (SARS-CoV-2), identificado na China no final de 2019, tem atingido fortemente a população. Os sintomas da doença aparecem em até 14 dias após contato com a cepa e englobam: tosse, febre, coriza, dor muscular, anosmia/hiposmia, dor de garganta e dispneia. ${ }^{1}$ As instituições de saúde, diante deste cenário, organizaram um novo ambiente para atender às demandas dos profissionais diretamente envolvidos na assistência a esses indivíduos. ${ }^{2}$

O Rio de Janeiro teve seu primeiro caso confirmado em viajante em fevereiro de 2020. Após este período, os casos incidentes no estado apresentaram curva ascendente, bem como o aumento de hospitalizações e de mortalidade. $\mathrm{O}$ registro atual de casos confirmados da doença na região é de 4.689.613, dos quais 140.537 evoluíram para óbito. ${ }^{3}$
Com o objetivo de minimizar os impactos negativos da pandemia e considerando que os profissionais de saúde são os mais expostos, foi essencial uma reflexão sobre a gerência do cuidado de enfermagem no que tange, em especial, à prevenção da contaminação e promoção da saúde desses trabalhadores.

O termo gestão do cuidado de enfermagem compreende a interligação gerencial e assistencial que envolve o trabalho do enfermeiro nos diversos campos de atuação. Ele é utilizado para caracterizar as atividades desse profissional em vistas ao planejamento das ações de cuidado, previsão e provisão de recursos e intensificação do trabalho interdisciplinar, objetivando uma assistência articulada. ${ }^{4}$

Assim, justifica-se este estudo pela importância de fortalecer o papel do enfermeiro e compartilhar experiências e desafios de uma enfermeira na condição de gestora de serviço em tempos de pandemia. 
Ressalta-se que se apropriou dos conceitos de Donabedian no que concerne os componentes de estruturas (características relativamente estáveis e necessárias ao processo assistencial, abrangendo a área física, recursos humanos), processos (prestação da assistência segundo padrões técnicocientíficos, estabelecidos e aceitos na comunidade científica sobre determinado assunto) e resultados (consequências das atividades realizadas nos serviços de saúde, ou pelo profissional em termos de mudanças verificadas no estado de saúde dos pacientes) para ancorar as discussões deste relato. ${ }^{5}$

Objetivou-se relatar a experiência de uma enfermeira atuante em uma enfermaria quanto aos desafios enfrentados e estratégias utilizadas na gestão do cuidado a pacientes suspeitos e confirmados de infecção por COVID-19 durante a pandemia do vírus no Brasil.

\section{MÉTODO}

Trata-se de um relato da experiência que visa contribuir para a discussão sobre a importância do enfermeiro na gestão do cuidado de enfermagem através das experiências, desafios e expectativas vivenciadas durante a pandemia da COVID-19 no Brasil.

O presente relato foi desenvolvido por uma enfermeira na condição de gestora Rev Enferm Atenção Saúde [Online]. Out/Dez 2021; 10(3):e202137 de uma enfermaria, de abril a julho de 2020, de um hospital do estado do Rio de Janeiro.

A instituição hospitalar possui total de 525 leitos, sendo que 166 foram destinados à assistência ao paciente confirmado ou suspeito da COVID-19.

O estudo não necessitou da aprovação do Comitê de Ética em Pesquisa, mas foram respeitados todos os preceitos da Resolução 466/12, do Conselho Nacional de Saúde.

\section{APRESENTAÇÃO DA EXPERIÊNCIA ESTRUTURA DO AMBIENTE}

Este relato foi desenvolvido em um setor de média complexidade de um hospital do Sistema Único de Saúde, referência no estado para COVID-19.

O cenário é uma enfermaria, composta por 16 leitos, estruturada para pacientes suspeitos ou confirmados da COVID-19.

A equipe de enfermagem englobou 37 técnicos de enfermagem e 13 enfermeiros, com escala de plantão $12 \times 60 \mathrm{~h}$, oriundos de enfermarias que interromperam seu funcionamento para suprir a demanda da COVID-19. Houve a necessidade de realização de capacitação desses profissionais e sensibilização sobre a importância dos EPI, fluxos e rotinas.

\section{PROCESSOS DE TRABALHO}

Processos organizacionais na pandemia 
$\mathrm{O}$ início da pandemia exigiu diversas mudanças na rotina da instituição. Estabeleceu-se que estariam na assistência aos pacientes suspeitos ou confirmados da COVID-19, apenas os funcionários que não se encontravam no grupo de risco. Os profissionais que se enquadravam nesse grupo (idosos, imunodeprimidos, pessoas com doenças crônicas) foram afastados ou realocados em setores que não haviam exposição aumentada ao vírus.

Os profissionais suspeitos de contaminação foram encaminhados para a triagem respiratória, realizaram teste para COVID-19, mantiveram isolamento domiciliar e controle pela instituição.

A adaptação diária da escala de serviço se fez necessária para a cobertura das lacunas deixadas pelos afastamentos. $\mathrm{O}$ remanejamento de profissionais de enfermagem de outros setores, por vezes, se fez necessário para que houvesse o quantitativo mínimo de funcionários nos serviços diurno e noturno.

Para o funcionamento da enfermaria, foi imprescindível a criação de fluxo de entrada e saída de funcionários e de pacientes; e de utilização dos equipamentos de proteção individual (EPI) durante a assistência. A elaboração desses fluxos contou com a parceria da Comissão de Controle de infecção hospitalar (CCIH) e do Serviço de Treinamento de Enfermagem da instituição e visou à estruturação do serviço e articulação da atuação da enfermagem.

A parceria da equipe médica quanto ao cumprimento dos fluxos foi importante para que não houvessem falhas ou quebras de barreiras entre as áreas limpas e contaminadas.

A participação das equipes multiprofissionais no feed back do processo de trabalho proposto foi essencial para a adequação do mesmo, quando necessário, e melhor adaptação das equipes às rotinas existentes.

\section{Otimização do cuidado através de capacitação frente aos novos fluxos e rotinas}

A assistência aos pacientes com COVID-19 exigiu a capacitação dos profissionais desde a higienização das mãos até o uso dos EPI.

As atribuições do enfermeiro que atua na gerência do cuidado perpassam pela conscientização da equipe sobre a necessidade de otimizar a demanda de cuidados para horários comuns. Escalar um funcionário da equipe para atender, no corredor/parte externa, as solicitações dos profissionais que estão dentro do isolamento foi uma estratégia eficaz para evitar a troca de EPI por esquecimento ou necessidade de novos suprimentos para a realização dos cuidados. 
A utilização da estratégia de concentrar os materiais como bombas infusoras, ventiladores mecânicos, carro de parada cardíaca e maleta de intubação rápida fora dos leitos de isolamento foi benéfica para o fluxo de atendimento, uma vez que esses materiais se encontravam em condições para o rápido uso.

Houve a necessidade de realizar reuniões com os chefes de serviços para a resolução de problemas de falta de materiais e insumos. Os setores de $\mathrm{CCIH}$, Central de Material, Almoxarifado e Coordenação de enfermagem estiveram presentes para que situações de escassez de materiais fossem resolvidas. Entretanto, a falta de insumos no mercado fez com que houvesse alteração de padronização durante o período, exigindo frequentes atualizações das equipes.

\section{Saúde mental dos profissionais de} enfermagem da linha de frente

Os profissionais de saúde da linha de frentes nos cuidados aos pacientes COVID19 estão entre os grupos mais expostos às consequências físicas e psicológicas desta pandemia. Eles vivenciam rotinas exaustivas que se aliam ao medo de contaminação. Assim, o amparo à saúde mental tornou-se prioritário ao que se refere às ações de apoio e estruturação daqueles que cuidam.

As equipes de enfermagem demonstram a sensação de impotência diante à letalidade da COVID-19. O cansaço, o distanciamento dos familiares, o medo da falta de EPI e a falta de adesão da população às recomendações governamentais somatizam o desgaste psicológico desses indivíduos.

Para minimizar a sobrecarga emocional e a exaustão desses profissionais, foi possível, junto à coordenação de enfermagem, aquisição de seis técnicos de enfermagem e seis enfermeiros, totalizando os cinquenta profissionais que compõem a escala.

A gestão do cuidado frente à sobrecarga psicológica das equipes de enfermagem exigiu um olhar criterioso para o indivíduo. A fim de proporcionar momentos de alívio emocional às equipes, os psicólogos disponibilizaram atendimento aos funcionários conforme demanda.

Ao refletir a respeito da gestão de quem cuida, é importante pontuar ações eficazes para se manter os profissionais protegidos de estresse e de uma saúde mental precária: assegurar informações de qualidade e fidedignas; estabelecer espaço para descanso e interação da equipe; manutenção da boa relação entre os colegas, possibilitando a ampliação de apoio social.

\section{RESULTADOS DA GERÊNCIA DO CUIDADO}

Gerenciar o cuidado de enfermagem frente a uma pandemia demandou muita Rev Enferm Atenção Saúde [Online]. Out/Dez 2021; 10(3):e202137ＩSSN 2317-1154 
cautela e determinação. Conscientizar os profissionais quanto a importância da adaptação às mudanças e novas condutas durante a assistência foi um trabalho diário junto às equipes.

Com o aumento dos casos incidentes e internações, não houve tempo hábil para estruturação física da instituição, assim como treinamento prévio das equipes multiprofissionais.

O planejamento do quantitativo dos insumos utilizados na assistência, bem como dos EPI necessários para a proteção das equipes foi um desafio semanal, uma vez que a conscientização dos profissionais para o uso racional desses materiais influenciava diretamente o quantitativo utilizado.

Apesar de ser uma enfermaria de média complexidade, o fato de estar relacionada a pacientes com COVID-19, tornou essencial a disponibilização de materiais referentes à intubação orotraqueal, punção venosa profunda e carro de parada cardíaca para as emergências clínicas.

Conscientizar os profissionais sobre a importância de se manter a tranquilidade frente a um momento de urgência clínica, implicou não apenas à realização de uma assistência eficiente e dentro dos protocolos, como também à garantia de uma correta paramentação e desparamentação.
A adesão das equipes às orientações referentes aos cuidados junto aos pacientes suspeitos ou contaminados aumentou diariamente, o que minimizou a exposição dos profissionais aos riscos existentes.

\section{DISCUSSÃO}

Este relato evidencia a importância do papel do enfermeiro na construção de um serviço e na atuação da equipe de enfermagem. A prática gerencial do enfermeiro envolve múltiplas ações de gerenciar cuidando e educando, de cuidar gerenciando e educando, de educar cuidando e gerenciando ${ }^{6}$, o que faz desse profissional uma peça indispensável na organização da assistência durante uma pandemia.

As atribuições do enfermeiro gerente permeia a estruturação do setor, a previsão e provisão de insumos, a organização da escala de trabalho da enfermagem, como também o processo de capacitação das equipes em vistas à proteção e promoção da saúde.

A liderança do enfermeiro demandou processos de gestão que vão além dos assistenciais rotineiramente conhecidos. O desenvolvimento de habilidades e competência se fez necessário para que os profissionais que se encontravam na linha de frente tivessem a estrutura necessária para a realização das suas atividades. 
Este relato de experiência corrobora com a publicação da Organização Mundial de Saúde, em parceria com o Conselho Internacional de Enfermeiros, e a campanha Nursing Now, com o apoio de governos e parceiros, o qual destacou os desafios e o valor da força de trabalho da Enfermagem globalmente. $^{7}$

A Organização Mundial de Saúde apontou para a necessidade de estratégias dirigidas por enfermeiros a fim de reduzir o consumo de diversos insumos através de preparação, prevenção e inovação dos recursos. $^{7} \mathrm{O}$ uso de critérios para a sua utilização é fundamental para que se possa aumentar a janela de proteção da equipe que se encontra na frente dos cuidados.

Garantir a segurança dos profissionais da equipe multiprofissional contra o vírus é assegurar que os mesmos não serão vetores de transmissão e que, como consequência, não adoecerão. Essa precaução torna-se benéfica, uma vez que permite a manutenção da equipe de saúde completa para a assistência na pandemia. ${ }^{8}$

Estudos recentes apontam que estar isolado, trabalhar em posições de alto risco e ter contato com pessoas infectadas são causas comuns de trauma e podem ter impacto direto nos trabalhadores da linha de frente, levando a problemas de saúde mental. ${ }^{9-10}$

A saúde dos profissionais da linha de frente merece grande atenção. Gerenciar o Rev Enferm Atenção Saúde [Online]. Out/Dez 2021; 10(3):e202137 estresse da rotina diária da equipe e ter um olhar para as dimensões física, psicológica, social e espiritual desses indivíduos é o maior dos desafios a ser alcançado.

\section{CONCLUSÃO}

A gestão do cuidado de enfermagem em um hospital referência da COVID-19 representou um desafio profissional. Estar junto com a equipe na perspectiva de minimizar as dificuldades e proporcionar um ambiente tranquilo para a atuação dos profissionais foi fundamental para uma assistência de qualidade.

O papel do enfermeiro gerente neste âmbito foi essencial para a estruturação do cuidado de enfermagem e envolveu a busca pela qualidade assistencial e de melhores condições de trabalho, a gerência de recursos humanos e materiais, a liderança, o planejamento da assistência, a capacitação da equipe de enfermagem, a coordenação da produção do cuidado e a avaliação das ações desenvolvidas.

\section{REFERÊNCIAS}

\section{Centers for Disease Control and} Prevention (CDC). Interim U.S. guidance for risk assessment and public health management of healthcare personnel with potential exposure in a healthcare setting to patients with Coronavirus Disease (COVID-19) [Internet]. 2020[acesso em 31 mai 20]. Disponível em: https://www.cdc.gov/coronavirus/2019ncov/hcp/guidance-risk-assesmenthcp.html 
2. Liu Y, Wang H, Chen J, Zhang X, Ke J, Wang B, Peng C. Emergency management of nursing human resources and supplies to respond to coronavirus disease epidemic 2019. Int J Nurs Sci. [Internet]. 2020 [citado em 28 set 2020]; 7(2)135-138. Disponível em:

https://www.sciencedirect.com/science/arti cle/pii/S235201322030051X

3. Ministério da Saúde (Brasil). Painel Coronavírus no Brasil [citado em 26 set 20]. Brasília: Ministério da Saúde; 2020. Disponível em: https://covid.saude.gov.br/ 4. Siewert JS, Rodrigues DB, Malfussi LBH, Andrade SR, Erdmann AL. Gestão do Cuidado Integral em Enfermagem: reflexões sob a perspectiva do pensamento complexo. Rev Min Enferm. [Internet]. 2017 [citado em 28 set 2020]; 21:e-1047. Disponível em: http://reme.org.br/artigo/detalhes/1185. 5. D'Innocenzo M, Adami NP, Cunha ICKO. O movimento pela qualidade nos serviços de saúde e enfermagem. Rev. bras. enferm. [Internet]. 2006;59(1):8488. Disponível em:

http://www.scielo.br/scielo.php?script=sci _arttext\&pid=S0034-

$71672006000100016 \& \operatorname{lng}=\mathrm{en}$.

6. Erdmann AL, Backes DS, Minuzzi

H. Gerência do cuidado de enfermagem pelo olhar da complexidade. Rev Bras Enferm. 2007 dez; 7(1): 1-12.

7. Cassiani SHB, Lira NJCG. Perspectivas da Enfermagem e a Campanha Nursing Now. Rev. Bras. Enferm. [Internet]. 2018 [citado em 28 set 2020]; 71 (5): 23512352. Disponível em: http://www.scielo.br/scielo.php?script=sci _arttext\&pid=S0034$71672018000502351 \& \operatorname{lng}=$ en.

8. Chang D, Xu H, Reabaza A, Sharma L, Cruz CSD. Protecting health-care workers from subclinical coronavirus infection.Lancet.[Internet].2020[citado em 28 set 2020];8(1):13. Disponível em:https://www.thelancet.com/action/show Pdf?pii=S2213-2600\%2820\%2930066-7 9. Miranda FMA, Santana LL, Pizzolato AC, Sarquis LMM. Condições de trabalho e o impacto na saúde dos profissionais de enfermagem frente a COVID-19. Cogitare Enfermagem. [Internet]. 2020[citado em 28 set 2020]. 25:e72702. Disponível em: <https://revistas.ufpr.br/cogitare/article/vie w/72702>.

10. Park JS, Lee EH, Park NR, Choi YH. Mental Health of Nurses Working at a Government-designated Hospital During a MERS-CoV Outbreak: A Cross-sectional Study. Arch Psychiatr Nurs. [Internet]. 2018 [citado em 28 set 2020];32(1):2-6. Disponível em: https://pubmed.ncbi.nlm.nih.gov/29413067 I

RECEBIDO: $28 / 09 / 2020$

APROVADO: $27 / 09 / 2021$

PUBLICADO: dez/2021 